\title{
Healthcare under Sanctions in Iraq: An Elective Experience
}

\author{
MUHAMMED AKUNJEE and ASIF ALI
}

Guy's, Kings and St Thomas' Hospital Medical Schools, London SE l 9RT

\begin{abstract}
As a consequence of the 1991 Gulf War and the ensuing UN sanctions, not only was the Iraqi government destroyed, but also the general infrastructure of the country was disrupted, with the civilian population and public services bearing much of the aftermath. Ten years after the war, the health system in Iraq is still in a perilous situation. The effects of sanctions have affected almost every aspect of medical care. There has been a mass exodus of health care professionals, many of whom were foreign nationals. Doctors' salaries fell rapidly to only $\$ 30$ a month, barely enough to buy the necessities of daily living. Iraqi hospitals have no access to foreign journals, textbooks or the internet; leading to a generation of out-dated and underskilled health professionals. Most worrying is the ever-present embargo on many essential medicines. Only one-third of the medicines are available for chemotherapy for the treatment of acute lymphoblastic leukaemia in children (UKALL 97 modified 99 protocol). At the AI-Mansour paediatric teaching hospital this shortfall has led to a substantial increase in childhood mortality, with disease-free survival rates falling to 25 per cent compared to 60 per cent in 1988 .
\end{abstract}

\section{KEYWORDS Childhood leukaemia Healthcare Iraq Sanctions}

\section{Introduction}

Iraq is $440,000 \mathrm{~km}^{2}$ in area, located in the Persian Gulf bordering Iran and Kuwait. The country is commonly known as the 'Cradle of Civilization', since in early times the land area was equivalent to Mesopotamia, the land between the rivers Tigris and Euphrates. Mesopotamia is regarded as the first land to be cultivated on this earth and where the first alphabet and primitive calendars were devised. ${ }^{1}$ In the Arab world, Iraq is known as AlJumhooriyah Al-Iraqi, or the People's Republic of Iraq, and has a population of around 21 million people. Its capital, Baghdad, is one of the oldest centres of trade on the earth and is one of the 18 provinces of Iraq; others include the famous areas of Karbala and Basrah.

After the 1970s Iraq experienced huge economic, social and political development. However, with the onset of the Gulf War in 1991, this immense growth ended, leaving the Iraqi population in a perilous situation. In 1989, the Gross Domestic Product (GDP) was US\$3510 per head, but by 1996 was below US $\$ 450$ per head. Infant mortality was 29 per 1000 in 1989 , but rose to 131 per 1000 under fives between 1994 and 1999. ${ }^{2}$ Many believe that the reason for this decline is the sanctions imposed on Iraq by the United Nations following the Gulf War, leading to inadequate health services.

On 6 August 1990, the UN Security Council ratified Resolution 661, imposing severe sanctions on all imports and exports to and from Iraq. ${ }^{3}$ Prior to this, oil revenues accounted for well over 90 per cent of Iraq's economy. Finances generated from oil exports were used to fund the import of food, medicine and equipment for the then modern health service. The extensive blockade on oil exports ravaged the country's economy, affecting both education and health service provision. It has been widely debated whether sanctions have played any significant role in weakening the Iraqi regime militarily and politically, but due to the 
indiscriminate nature with which they have been applied, the impact of sanctions has not been restricted to the government; civilians have borne much of the suffering. As the World Health Organization Division of Emergency and Humanitarian Action commented:

The six-week war in 1991 resulted in the large-scale destruction of military and civilian infrastructures alike. In general, civilian populations were, subsequently more affected by the consequences of much destruction than the military populations ... The reduction in the import of medicines, owing to a lack of financial resources, as well as a lack of minimum health care facilities, insecticides, pharmaceutical and other related equipment and appliances, have crippled the health care services, which in pre-war years were of a high quality. Assessment reports rightly remarked that the quality of health care in Iraq, due to the six-week 1991 war and the subsequent sanctions imposed on the country, has been literally put back by at least 50 years. ${ }^{4}$

Iraq was thrown into turmoil. Its military might was destroyed and the infrastructure of the country was devastated. The civilian population bore the brunt of the aftermath of the war; hospitals, schools, transport links and communications were all affected. Because of the breakdown of the health system of Iraq diseases such as malaria, typhoid and cholera, which were once almost under control, reappeared at epidemic levels. Ten years after the Gulf War, it might be hoped that the situation in Iraq would have improved somewhat. This article portrays the current Iraqi health situation through the experiences of two UK medical students who spent part of their final year medical elective in Iraq.

\section{On the Ground in Iraq}

The many reports and articles we had read on the misfortunes of the Iraqi nation became a tangible reality. It is very difficult to appreciate the huge ramifications that sanctions have had and are still having on the Iraqi civilian population without actually visiting the country. There is a sense of insecurity and despair throughout the nation. Most people's life savings have vanished following the collapse of the once strong Iraqi dinar. In 1990, one dinar was equivalent to four US\$. Following the war in 1993, the value of the dinar fell to just over 50 dinars to one US\$. Before the oil for-food programme in 1996 was instigated, the Iraqi dinar further fell to 1,000 dinars to one US\$. By August 2001, the value was closer to 2,100 dinars to one US\$. The Director of the United Nations Centre for Human Settlements (UNCHS) comments that:

In the 1980s, the dinar was strong, families were okay. Now, people live on ten USD per month salaries. People are selling jewellery, carpets, air conditioners. The middle class is in poverty now; they have had to sell their houses, apartments, etc. ${ }^{5}$

The prices of basic commodities such as wheat, rice and sugar soared. For example, wheat flour cost 2.4 dinars per $\mathrm{kg}$ in August 1991, ${ }^{6}$ by May 1996, 240 dinars per kg, an increase of 100-fold. The price of rice increased from 4.1 dinars per $\mathrm{kg}$ to 350 dinars per $\mathrm{kg}{ }^{7}$ Because of the economic sanctions imposed on the Iraqi government resulting in the suspension of the main export, oil, and the decline in the value of the Iraqi dinar, the buying power of the country weakened and food could only be imported in small quantities. In 1996, the UN introduced the oil-for-food programme, which was designed to stop further 
deterioration of the Iraqi health and economic situation, allowing Iraq to export oil with the proceeds being paid into an account administered by the UN.

Despite this arrangement, the Iraqi economy has basically collapsed. An economic downturn has profound effects in any society, which can manifest themselves in many different ways. Economics and health are deeply intertwined; a poor country with low food stocks would almost certainly suffer increased levels of malnutrition and ultimately increasing mortality. Prior to the UN sanctions, Iraq had an advanced and efficient health care system providing a comprehensive range of services. Over 90 per cent of the population had access to primary health care, with a full childhood immunization schedule. ${ }^{8}$ Childhood mortality has increased from 47 per 1,000 live births before the war, to 108 per 1,000 live births post-war. ${ }^{9}$

\section{The Iraqi Health System}

Ultimately, the healthcare any country can provide is fundamentally dependent on the level of education of its doctors in addition to technological and pharmaceutical limitations. In Iraq, doctors undergo a six-year intensive medical training programme. This starts with a three-year foundation course in basic medical science, followed by two years of fully clinical study, with the final year as a resident-assistant on the ward. There are three medical schools in Baghdad: the Al-Mustansirriya University, the University of Baghdad Medical School and the Kindi Medical School. There are four or five medical schools outside Baghdad in areas such as Basra and Mosul. Since the war, the average medical school intake has increased from 250 to 400 students per school, causing concern amongst many medical specialists who believe that quality has been sacrificed for quantity. Despite this increase, there have always been few facilities available for students. Since the onset of sanctions, medical textbooks, upto-date medical journals and modern equipment have all been restricted from entering Iraq. The few original texts that do exist are cherished immensely and photocopied numerous times for distribution amongst the students.

The transition from medical student to doctor should be a time of celebration, but in Iraq many graduates choose to leave the profession after completing their degrees. The prospect of one in three nights on-call for a mere US\$12 a month and a severe lack of further opportunity greet the newly qualified. Many simply leave, since there are less strenuous jobs elsewhere.

\section{Further Educational Opportunities}

The many educational opportunities that are available in the UK for health professionals are largely taken for granted. The internet has provided medical professionals all around the world with the opportunity to read and scrutinize management protocols for many different diseases and evaluate the evidence-based practice for each. However, in Iraq access to the internet is strictly controlled and limited. Hardware restrictions caused by the economic sanctions have seriously restricted internet accessibility and use. The government provides only a handful of internet terminals at a few governmental offices, including the Baghdad Central Library. However, access is only possible through a government appointed official, resulting in restricted and censored internet use which is of no real benefit to most doctors.

The shelves of the medical libraries are empty, devoid of any up-to-date medical journals since all subscriptions have been terminated after the war. Many doctors rely on the good will and charity of fellow Iraqi professionals living abroad to provide journals and upto-date medical texts when visiting the country. Specialists are unable to travel abroad to attend international conferences since very few countries are willing to grant visas to Iraqi 
citizens. Even if this were possible, the huge costs travel entails would hamper most if not all of the health professionals. Thus a generation of under-skilled, outdated and disillusioned doctors is being created.

Compounding the burden on doctors is the extreme shortage of allied health professionals in Iraqi hospitals. Doctors are increasingly forced to undertake additional tasks for which they have had no training, adding to the stresses of the job and further fuelling the mass exodus.

\section{Allied Health Professionals}

In the UK National Health Service, in particular in the hospital setting, there are numerous other specialist health professionals, such as nurses, dieticians, psychologists, phlebotomists and physiotherapists, who play vital roles in a multidisciplinary approach to medical care. This used to be the situation in Iraq, but following the Gulf War there has been a huge shortfall in these professionals. On many wards it is usual to find only one nurse responsible for all the patients.

Before the war, Iraq employed large numbers of foreign nurses, all of whom had to leave the country as a result of sanctions. Of the Iraqi nurses that remained, many left their jobs because of the poor pay (up to US\$5 per month) and deteriorating working conditions. Of the few who now enter nursing, many do so simply because there are very few job vacancies elsewhere. Those that complete their training find that they no longer perform the ward duties they were originally trained for. Their role now is makeshift receptionists, collating and storing the medical notes for each patient and occasionally helping doctors to take blood. Much of their original responsibility has shifted to the doctors and also to the patients' families.

Desperate mothers lie beside their sick children, while their fathers wait outside. The mothers have become the much-needed nurses and the fathers the porters. At the beginning of each day, the mothers are handed the drugs that need to be administered during the day. They remain on hand at the side of the bed to feed, wash and care for their child. Whenever a blood sample is taken or an X-ray is required, the fathers are called to take the blood to the laboratory or the patient to the radiology department. Fathers often sleep in the corridors of the hospitals, keeping themselves near at hand in case the doctors require them. Without such assistance, doctors are unable to care for their patients.

\section{Laboratory Facilities}

Irrespective of experience, doctors are still dependent on investigative tools in arriving at a conclusive diagnosis. Investigations such as laboratory tests, X-rays and CT scans have become routine procedures in the developed world. Such facilities are still available in Iraq. However, due to poor maintenance, costs and a lack of technicians, the use of such tests has been scaled down markedly since the Gulf War. Most doctors cite sanctions as responsible for this. A survey ${ }^{8}$ estimated that there had been at least a 50 per cent drop in the provision of laboratory services due to the lack of equipment and chemicals and also highlighted a fall of up to 60 per cent in surgical interventions because of a lack of essential supplies such as anaesthetic agents, sterile gloves and surgical instruments.

Before the Gulf War, Iraq had free access to UK- and US-based companies for drug imports, but the availability of medications in Iraq has been limited following the imposition of sanctions. Restrictions were placed on drugs that were believed to have the potential for a dual purpose: for the manufacture of instruments of warfare as well as their medicinal properties. A UN appointed drug committee, which takes anything up to five months to give 
its approval, must initially approve newly negotiated drug contracts. This process is bureaucratic and on many occasions contracts are flatly denied. This has led to perhaps the greatest shock to the Iraqi health establishment, the absence of many essential medications.

\section{Drug Shortages}

Much has been reported on the problem of drug shortages faced by Iraqi doctors, but no studies have detailed the specific magnitude of this problem. Many commentators report a lack of medication for cancer chemotherapy being allowed into Iraq, citing an increase in childhood malignancy ${ }^{10}$ to further their case. However, even though this shortfall in chemotherapeutic agents is very real, perhaps more worryingly, medication for countless other more common conditions are also severely lacking.

Common bacterial and fungal infections, usually easily controllable with appropriate antibiotic and antifungal agents, have become fatal conditions. Patients presenting with infection are empirically treated with gentamicin and ampicillin at the onset of symptoms, since no alternative antibiotics are available. If there is no response, the infection spreads and the patient more often than not dies. The only antifungal available is ketoconazole, but this is rarely used due to problems of hepatic toxicity. More efficacious medication such as amphotericin B and fluconazole are simply unavailable. It is feared that the overuse of certain medications will lead to antibiotic resistance in the long-term. It seems only a matter of time before infectious epidemics become widespread in Iraq with the lack of appropriate treatment available.

Day-to-day complaints of pain, nausea and vomiting have not been spared the medicinal embargo. For pain sufferers, only paracetamol and ibuprofen are available. Stronger analgesics such as codeine phosphate and morphine are unavailable. For nausea and vomiting only metoclopramide (maxolon) is available. If symptom control is not achieved there are no alternatives. Patients are left to cope to the best of their ability with their problems, since nothing more can be done.

For those children in Iraq who have been unfortunate enough to be diagnosed with childhood malignancy, infection, pain, nausea and vomiting control are a major problem and essential chemotherapy medication vital for the remission of their disease is for the most part unavailable. From ashort study we performed in Iraq, looking in particular at the management of paediatric acute lymphoblastic leukaemia, we found that over 66 per cent of chemotherapy medication required of the current UKALL 97 (modified 99) protocols were unavailable. The only drugs that were currently in use were the steroids, prednisolone and dexamethasone, in addition to methotrexate and co-trimoxazole. Drugs such as Lasparaginase, cyclophosphamide, 6-mercaptopurine (which forms the basis of maintenance therapy), vincristine, cytarabine and doxorubicin are unavailable. These shortages have severely disrupted the management of paediatric acute lymphoblastic leukaemia, so much so that disease-free survival has plummeted from just over 60 per cent ${ }^{11}$ in 1988 to an estimated 25 per cent at present.

There have also been difficulties with drug storage, quality, administration and monitoring of blood levels. With regards to drug storage, because of continual problems with the electricity supply, many medicines are kept at non-optimal temperatures, affecting drug efficacy. Drug quality has also been a problem since the Gulf War. Due to the economic downturn, the Iraqi government has turned to countries such as Russia, China and other eastern-bloc nations for drug supplies. Drugs from these countries are often of a very poor standard; we saw many examples such as saline bags contaminated with pyrogens leading to fever and rigors in the recipients. Drug administration is also a problem. Aseptic technique is 
often impossible due to equipment shortages and the technology for the monitoring of blood levels for drugs such as methotrexate and gentamicin is unavailable.

\section{Proposals}

We have described only a snapshot of the problems we encountered on our visit to Iraq; the question raised is what can be done to alleviate the suffering. In the present situation and political climate the doctors working to alleviate the health deterioration in Iraq face a multitude of problems. It is therefore necessary to decide on priorities for the improvements that can be made.

First and foremost, health professionals need a continuous supply of all medication needed to treat common diseases. This can only be achieved by full co-operation between the UN and the Iraqi government in relaxing some of the sanctions imposed on medicines. Second, the education of doctors has to be improved. Iraqi doctors should be given full access to current journals and research and opportunities to attend international conferences. Many are ten years behind in their knowledge and a great deal of effort will be needed to correct this gap. Third, allied professionals such as nurses need to be attracted back to Iraqi hospitals by improved pay and working conditions. This would enable Iraqi doctors to provide a comprehensive package of care for their patients. But all this can only be achieved with the rebuilding of the Iraqi economy. It is clear that the Iraqi health system is in complete disarray. Many doctors are unsure whether to carry on practising in the current climate, or adopt the easier option of leaving altogether. The health system is currently almost solely functioning through the efforts of the hard-working and committed Iraqi doctors, without whom no healthcare at all would be provided. It is apparent that Iraqi health professionals need help, financially, educationally, or even simply sympathetically. Despite their problems and experiences, health professionals in Iraq do not seem to have any significant political voice as to their predicament. It is clearly evident that the civilian population, who had no role to play in the election of their leader, is bearing the brunt of the sanctions.

We feel that it is now time to question the moral basis of restricting essential drugs with known and proven benefit of cure from entering Iraq. Is it not a founding principal of medicine to alleviate suffering and provide cure for the people? If this is the case, then why is it that the medical profession in the UK as a whole has remained silent about the reality in Iraq? Do we not, as doctors, have a duty of care to all people, at home, or abroad? Is not 11 years of suffering and death long enough for us to idly stand by and take no action? We have all seen how the leader has remained, yet millions have not. It is now time for the western world to act.

\section{Acknowledgements}

We would like to express our gratitude to the Cancer Research Campaign and the Leukaemia Research Fund for providing elective bursaries to enable our visit to Iraq. We would also like to thank the numerous medical professionals in Iraq who facilitated our stay and made our visit a most interesting and enlightening experience.

\section{References}

1. Iraq and its history. Encyclopaedia Britannica. 1997-2002. At: www.britannica.com.

2. UN Food and Agriculture Organization. Technical Co-operation Programme: 
Evaluation of Food and Nutrition Situation in Iraq. Rome: FAO, 1995: Table 28. 3. UN Security Council. Resolution 661. New York: UN, 6 Aug. 1990: paragraphs 3-4.

4. WHO’s Humanitarian Activities in Iraq under SCR 986. Geneva: WHO, April 1998.

5. Institute for Policy Studies. Iraq Trip Report 27 August - 6 September 1999. At: http://www.ips-de.org/reports.

6. Dreze J, et al. Hunger and poverty in Iraq 199 1. World Development 1992, 20:921-45.

7. Boone Gazdar, et al. Sanctions against Iraq - Cost of Failure. Centre for Economic and Social Rights, Nov. 1997. At: http://www.cesr.org/publications.htm.

8. World Health Organization. The Health Conditions of the Population in Iraq since the Gulf Crisis. Geneva: WHO, 1996.

9. Ali M, et al. Sanctions and childhood mortality in Iraq. Lancet 2000; 355: 1851-7.

10. Ciment J. Iraq blames Gulf war bombing for increase in child cancers. BMJ 1998; $317: 1612$.

11. Al-Attar A, Hilmi F, et al. Long term survival of childhood acute lymphoblastic leukaemia in Iraq. J. Fac. Med Baghdad 1996; 38: 172-8.

(Accepted 8 March 2001)

Muhammed Akunjee is a final year medical student at Guy's, King's and St. Thomas' Hospitals in London and a member of Medact. He was awarded a Leukaemia Research Bursary and the Rayne Institute Elective Award to carry out a project whilst on his elective in Iraq. He won the War Memorial Exhibition Prize for pre-clinical examination results, a distinction in Psychology and Sociology and the Kings College London Lightfoot Award.

Asif Ali is a final year medical student at Guy's, King's and St. Thomas' Hospitals in London and is a member of Medact. He received a Cancer Research Award and the Rayne Institute Elective Award to carry out a project whilst on his medical elective in Iraq. He gained a First Prize and distinction in Neurology and was runner-up for the Bhattia Medal and John Ellis prizes in Paediatrics. 